\title{
The Development and Understanding of the Concept of 'Experience' in John Dewey's Theory of Experiential Learning Pavel Votava
}

\begin{abstract}
The aim of the article is to show the meaning and use of the concept of 'experience' in different areas in the context of John Dewey's Theory of Experiential Learning. In the introduction, the American philosopher and educator John Dewey and the circumstances leading to pragmatic pedagogy are introduced. In each chapter the author describes the development and understanding of the concept of 'experience' in connection with the specific Dewey publications related to his theory of experiential learning. The first chapter is about the book Democracy and Education, the second chapter deals with the book Experience and Nature, the third chapter handles the book Art as Experience, and the final one presents the book Experience and Education. In conclusion, the author summarises his findings.
\end{abstract}

Key words: John Dewey, experience, experiential learning, learning by doing, pragmatic pedagogy

\section{Introduction}

John Dewey (1859-1952) was one of the most influential American philosophers of the first half of the 20th century. His greatest contribution can be observed in the field of pedagogical sciences. After completing his studies at the University of Vermont, he himself gave lectures at several colleges. He is considered to be a significant personality of pragmatic pedagogy. At the turn of the and 20th century, this field of pedagogy dealt with a significant change in the understanding of the pupil as a subject of education. Dewey, by focusing on the interests and experience of pupils, strongly advocated the development of paedocentrism, which, he says, is a 'cure' for traditional pedagogy and its methods. ${ }^{1}$

Dewey and other advocates of pragmatic pedagogy argue that in the traditional concept of education, a pupil is viewed as an object of education and, as such, he is doomed to a passive role and led by the teacher as the highest sovereign authority. The teacher's authority is strengthened by constant supervision, punishments (exceptionally, even by physical punishments), prohibitions, 
and denial of freedom. This logically leads to the suppression of creativity and initiative of pupils who, consequently, suffer from exaggerated formalism and emphasis on the theoretical knowledge of the content of education with a minimal application of acquired knowledge in practice. Traditional pedagogy systematically avoids responsibility for finding suitable conditions which would help to gain experience for further pupil growth. The school environment of benches, boards, and a small school yard is considered to be sufficient in the traditional sense. In traditional pedagogy, there is no remark about the teacher initiating the arrangement of the conditions of the local environment (physical, historical, economic, professional, etc.) for the purpose of their utilisation as educational resources. ${ }^{2}$

Dewey argues that, compared to the traditional concept of education, the pragmatic concept of education (respectively the progressive concept of education) opposes exaggerated formalism and disagrees with the emphasis on strict discipline, passive learning and 'blunt drill'. rather than external discipline favours free activity, and instead of learning by drill from texts and teachers he prefers learning through experiences. ${ }^{4}$ Man, on the basis of experiments, attempts, and mistakes, comes up with different ideas, opinions, and laws that help him to orient himself in a specific situation. ${ }^{5}$ Dewey's educational system is based on the necessity of combining education and experience that we must always keep in mind. This demanding requirement (which has to be met by the educator) is, according to Dewey, the reason why the pragmatic concept of education represents a more difficult approach than the traditional education system. ${ }^{6}$

I will consider the research question in relation to Dewey's Theory of Experiential Learning in which the necessary interconnection of theory with practice is emphasised. How has the concept of 'experience' developed in publications that include knowledge of the theory of experiential learning? Among his key publications which include knowledge about the theory of experiential learning and the concept of 'experience' are Experience and Education (1938), Art as Experience (1934), Experience and Nature (1925), and Democracy and Education (1916). ${ }^{7}$

\section{The Term 'Experience' in Democracy and Education}

The book Democracy and Education, published in 1916, is considered to be the major and the best-known work of John Dewey. Most philosophers and educators consider it to be the pivotal text of pragmatic pedagogy. Dewey here criticises the outdated and ineffective Herbartian approach and sums up all his knowledge of education. The problem of education is an exaggerated focus on the future and preparation for adulthood. Dewey promotes the interests of the child, especially the experience of a childhood lived in fullness. The quality of school education should be judged on the basis of the motivation given to pupils in the area of their own improvement and development, and on the basis of the fact saying how successful the education is in delivering conditions that will transform the desire for growth into real action. Dewey also emphasises the irreplaceable role of the individual in participating and solving society's problems (in order to develop democratic values).

Dewey emphasises plasticity presented as the adaptability of the immature being to growth.

Cf. John DEWEY, Experience and Education, New York: Kappa Delta Pi, 1938, pp. 40-41.

Cf. František SINGULE, Americká pragmatická pedagogika, Prague: Státní pedagogické nakladatelství, 1990, p. 23.

Cf. DEWEY, Experience and Education..., p. 19.

Cf. SINGULE, Americká..., p. 29.

Cf. DEWEY, Experience and Education..., p. 40.

Cf. ibid., p. 7. 
However, he does not mean the ability to accept change under external pressure. It is basically about learning from experience, the ability to preserve something that will be beneficial when facing problems in later situations. This means to have the ability to modify behaviour based on past experience and the ability to develop dispositions which allows the acquirement of habits. ${ }^{8}$ Habit is, above all, a form of skill or efficiency in behaviour. Habit represents the ability to use natural conditions as a means to certain goals. Education is often defined as the acquisition of habits leading to the adaptation of an individual to his or her environment. The word 'adapt' is used in the active sense of control and management of the means to achieve the goals. If we understand the term habit only as a change that has been induced in the organism and ignore the fact that this change lies in the ability to influence the subsequent changes in the environment, we will come to the conclusion that the term 'adaptation' means conformity to the environment. But Dewey talks about the adjustment of an individual to outside conditions. ${ }^{9}$

According to Dewey, the education of pupils is a constant reorganisation or reconstruction of experience that enriches its meaning while enhancing the ability to direct the following experience. ${ }^{10}$ Gaining experience through an active process takes some time. The following experience complements the experience already gained and clarifies the relationships in it. Later activity thus consolidates and complements the meaning of earlier activities. ${ }^{11}$

Experience in its essence involves a combination of active and passive elements. From an active point of view, experience is 'trying' or experimenting. The passive aspect is 'undergoing'. If we gain experience with something, it means that we have influenced it in some way, somehow worked with it, and then found the results and consequences of our work. ${ }^{12}$ However, the mere activity does not yet lead to experience. It often distracts us and drains our forces. Experience thought of as 'trying' means change, but unless this change is consciously associated with the consequences of it, it is just a minor transition. However, if the action is continued even with the consequences, that is, if the change achieved by activities is reflected in the change that occurs in the particular individual, then the right sequence of activities becomes relevant. Dewey gives an example of a child who wants to put his or her hand in the fire. When a child puts his or her hand in the fire, it is not experience. Experience will happen if this movement is associated with the pain the child undergoes as a result. From this moment, putting a hand in the fire is, for the baby, associated with the possibility of the burn. ${ }^{13}$

The term 'learn from experience' means, in Dewey's view, creating a link, both backwards and to the future, between our actions and influence on things and the pleasant or unpleasant experiences that represent the consequences. Under such conditions, activity becomes an attempt. It's an experiment with the outside world to find out how this world is. These experiences become lessons leading to the discovery of interconnection between things. ${ }^{14}$

Dewey also describes general mental steps in creating experience:

1. Complexity, confusion, and doubt resulting from a situation we do not know;

2. Speculations and attempts carried out in order to interpret known elements that we think will lead to certain consequences;

8 Cf. John DEWEY, Democracy and Education. An Introduction to The Philosophy of Education, New York: The Macmillan Company, 1916, pp. 52-53.

9 Cf. ibid., pp. 54-55.

10 Cf. ibid., pp. 89-90.

11 Cf. ibid., pp. 91-92.

12 Cf. DEWEY, Democracy..., p. 163.

13 Cf. ibid.

14 Cf. ibid., p. 164. 
3. Careful exploration, that is, examining, investigating, and analysing all considerations that could define and clarify the problem;

4. Developing a general hypothesis that is gradually refined and processed by supporting it with other facts;

5. The created hypothesis is used as an action plan to address the given state of affairs. ${ }^{15}$

\section{The Term 'Experience' in Experience and Nature}

As the title of the book suggests, the key issue is the mutual relations of experience and nature, and there is an obvious attempt to make the reader look at these phenomena in a new way. Based on empirical naturalism, Dewey analyses experience and examines their influence on current tendencies in the individual's behaviour. Dewey also discusses topics in the field of epistemology, metaphysics, and philosophy in this book. One also finds treatises on art, morals, and values in it. Dewey deals with the question of the relationship between experience and nature. He claims that experience can be a means of revealing natural facts. Experience is not a 'veil' that covers up the deeper meanings of nature; on the contrary, experience has the potential to penetrate those meanings, it helps us to understand them better. Dewey highlights the 'history of nature' and the continuity of changes from the beginning to the end. The results of experiences (created in cooperation with nature) can be considered the tools, techniques, and mechanisms that people need for their lives. ${ }^{16}$ For example, a geologist living today is able to tell us not only about facts that happened long before he was born but also about events that happened millions of years before the first humans appeared on Earth. He begins with the study of 'material of experience'. $\mathrm{He}$ examines the composition of the Earth's crust, minerals, and rocks. Then he consults the gained knowledge with his or her colleagues specialised in other disciplines in order to get the most accurate data. From the data results, he can reconstruct events that have happened in the past. ${ }^{17}$ Dewey describes actual experience as phenomena representing a number of changes in which the goal is consumption and fulfilment. The individual tends to repeat them and make them stable. It is obvious that an individual participates in the emergence of new situations and experiences. The way he acts is influenced by his or her previous experience which also affects his or her current behaviour. Although Dewey does not refer directly to Darwin's evolutionary theory, he points to the fact that every form of life in the lower organisms leaves a trace in evolutionary higher and more advanced organisms, including us. An example may be, for example, the suction or grasp reflex in infants or the self-preservation instinct in the adult population..$^{18}$ Dewey divides experience into sovereign, absolute experience and human experience. Absolute experience should be the stability and instability of the world and all its experience. Absolute experience is the only one ever perfect. It is unlike human experience, which is temporary, full of mistakes, conflicts, and contradictions. ${ }^{19}$

\section{The Term 'Experience' in Art as Experience}

Art as Experience, published in 1934, had a significant impact in the field of aesthetics and philosophy of art at the end of the first half of the 20th century. It deals with the theory of aesthetic

15 Cf. ibid., p. 176.

16 Cf. John DEWEY, Experience and Nature, Chicago: Open Court Publishing Company, 1929, p. 1a.

17 Cf. ibid., pp. 3a-4a.

18 Cf. ibid., pp. 246-247.

19 Cf. ibid., pp. 59-60. 
experience. This theory seeks to understand what is important and characteristic in art and in the process of its formation in its entirety. He describes experience as a 'product' that arises from the continuous cumulative interaction of the individual with the world. We put our experience into artwork and in this way we allow people to share them. The world of art is often identified with the existence of buildings, books, paintings, or sculptures, which are separate from human experience even if it is obvious that these are the consequences of actual life experience. The task of aesthetics is to restore the relationship between cultivated experience, such as artwork, and experience in everyday life. According to Dewey, artwork is both the outcome and the content of experience. ${ }^{20}$ Every living individual consciously or unconsciously tries to adapt to the environment in which he lives. At the same time, he tries to achieve balance and harmony with that environment. Balance is the result of a dynamic solution to the existing stress. Aesthetic experience includes three essential factors. These are action, feeling and sense. Aesthetic experience would not happen in a world that was already 'finished', as it would not be possible to insert any new ideas and solutions to the new problems. The transition from disruption to the restoration of harmony provides the most intense experience for man. The feeling of happiness is the result of deep fulfilment in which one as a whole being adapts to the environment. ${ }^{21}$

The concept of aesthetic experience is a challenge to philosophy because it can be developed freely in the same way as experience. Philosophers must therefore examine the aesthetics to find the meaning of experience. Aesthetic theories attempt to explain aesthetic experience. Aesthetic theories can be classified according to the individual emphasised elements. ${ }^{22}$ Due to the fact that art based on aesthetic experience often gives us a sense of greater understanding to nature and people, some philosophers see art as a kind of knowledge that is superior to science. ${ }^{23}$

Dewey believes that the sources of aesthetic experience are also found in animals. Animals often reach the unity of experience that people are losing in their 'disturbed' working lives. A living animal lives in present and uses all its senses for it. It combines the past and the future in the current behaviour. Similarly, human beings have aesthetic experience that can be unified if people are aware of their social environment. This vigilance is a dual action - it includes anticipating and preparing for the future. People do not use their senses to store information only. Most of all, our senses force us to think and they prepare us for a possible action. Experience is an indicator of the level of active engagement with the world. Knowing the world and yourself is, according to Dewey, the beginning of art. ${ }^{24}$

Dewey goes back to the basic notion of experimental learning theory, to the concept of experience. Experience can be, for example, transforming the material into a particular product, playing chess, writing a book, or solving a problem. Such experience is complete, it has its own individual quality and self-identity. The interaction of an individual with his or her living conditions is a constant process so experience is gained on a regular basis. On the other hand, inchoate experience is understood as beginning and undeveloped experience. The individual is still unfocused at this stage and is unlikely to complete the goal he wants to accomplish. It is only 'early experience' that is not finished. Experience is also a reflection of other experiences that contain individualising quality. Dewey believes his theory of experience is consistent with the usage in everyday life even though it is at odds with how other philosophers talk about experiential learning. Dewey

20 Cf. John DEWEY, Art as Experience, New York: Penguin group, 1934, p. 3.

21 Cf. ibid., pp. 16-17.

22 Cf. ibid., pp. 274-275.

23 Cf. DEWEY, Art..., pp. 288-289.

24 Cf. ibid., p. 19. 
understands life as a story with its own plot, beginnings, conclusions, and dynamics. Every life has a unique quality. ${ }^{25}$

In experience as a whole, each of its sub-parts freely spreads into the following life issues and, at the same time, it carries the previous content. These parts fit into a long-lasting whole. There are no empty spaces or mechanical connections in the experience. There are only pauses, 'resting places', summarising the existing process of storing experiences in experience and preventing the dispersal or loss of information. ${ }^{26}$ Dewey claims that every single experience is anchored, respectively settled, and included in the experience structure of an individual. This can be achieved through the energy-producing experiences. According to Dewey, energy is 'the driving force' or the activating potential of an experience which an individual transforms into experience. However, energy can cause chaos and conflict. Although it is sometimes painful, it is a sign of development of experience and it is a part of a concrete experience. ${ }^{27}$

Each experience must meet the following two basic conditions which determine its existence.

1. Experience is the result of interaction between the individual person and the particular environment where the individual lives, that is, without any interaction with the environment one cannot gain any experience.

2. Experience has its structure that contains various relationships. The scope and content of relationships are an indicator of the importance of experience. If an experience is not included in the individual's existing experience structures, it will not have meaning for him, it will not make a sense. ${ }^{28}$

Works of art are an important example of experience. Here the individual elements contained in these works are united. Unity of experience, which is not exclusively emotional, practical, or intellectual, is determined by the only ubiquitous state. But no experience has unity without aesthetic quality. In aesthetic experience, there is an interest in the connection between every contemporary experience and the previous experience. Non-aesthetic experience is between two poles. The first is their free sequence which does not begin or end in any particular place. The second is their limitation given by the mechanical joining of their parts. ${ }^{29}$

\section{The Term 'Experience' in Experience and Education}

Experience and Education, published in 1938, is the most significant for Dewey's philosophy of education compared to Dewey's other works. In the first half of the 20th century, it was a strongly relevant contribution to US education, which understood the pragmatic concept of education as a 'new formation. ${ }^{30}$ In the book we find an analysis of both traditional and pragmatic education. However, the author emphasises that the values of none of these streams are sufficient individually. Both educational systems are key in the theory of education. ${ }^{31}$

Dewey justifies the need for the theory of experiential learning for contemporary pedagogy. To understand the relationship between education and personal experiences, we need to understand what experience is. The belief that true education comes through experiences does not mean that all experiences are true, real, or educational in the same way. Therefore, experience gained from

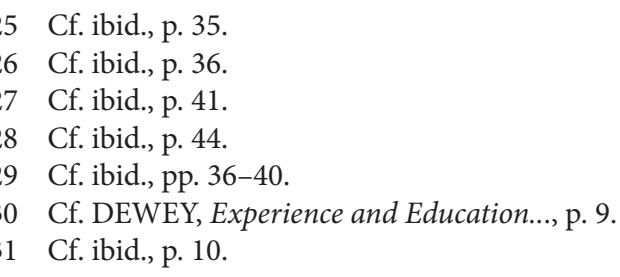


such experiences cannot be understood in the same way as education. Some experiences are not educational and as such they hold back or distort the growth of more advanced experiences. They may cause recklessness or produce a lack of sensitivity. They can also limit the possibility of gaining more experience in the future. According to Dewey, the formation experience should be immediately joyful and enjoyable, and should encourage the shaping of interested and positive changeable attitudes, as these attitudes and opinions then act in forming subsequent experiences. ${ }^{32}$

Experiences can be separated from one another. Although every one of them is acceptable or even exciting, they are not cumulatively linked to each other. The energy of these experiences is then wasted or scattered, and the individual becomes distracted. Each experience should be lively, fresh, and interesting. Their disconnection, though, can artificially generate scattering and disintegration of behaviour. The consequence of such a formation of these habits is also the inability to control future experience. ${ }^{33}$ Dewey also highlights the defective and bad character of experiences in terms of links with other experience. It depends on the quality of experience which has two aspects - acceptance or rejection and the influence of experiences. According to Dewey, an educator is responsible for this influence. His or her job is to create a specific kind of experiences that are not rejected by the student. On the contrary, those experiences make him engaged in activities, and in a such way, they make him immediately ready to acquire desirable future experience. Independently of our wishes or intentions, the existence of experience continues in further experience gained later. The central problem of education based on experience is the choice of a kind of contemporary experience that will live fruitfully and creatively in the following experience. ${ }^{34}$

In addition, Dewey discusses the criteria of experience starting with the concept of the experience continuum. By this term Dewey understands the principle explaining how the various kinds of experience are linked to each other. Each kind of experience is influenced by the previous experience and at the same time it modifies the quality of experience that will follow. ${ }^{35}$ For example, children's educational process is characterised by the development, that is, by the active principle of growth. Development or growth, not only physical but also intellectual and moral, is one of the examples of the experience continuum. What is important is the specification of the direction of growth. ${ }^{36}$

In every individual's pursuit of achieving a particular goal, it is possible to distinguish which kinds of experience are valuable for education and which are not. According to Dewey, this is a basic criterion of experience. Experience positively or negatively affects the attitudes of a person in order to help him assess the quality of other experiences by raising certain preferences and aversions. It also makes the action easier or more complicated. ${ }^{37}$

Each kind of experience influences at a certain level the objective conditions in which the individual gains further experience. Dewey illustrates this as an example of a child who, while learning to speak, acquires new skills and needs. But at the same time, he extends the external conditions of the following learning. Similarly, he opens the new possibilities for himself when learning to read. Another example is the decision of a person for a particular profession. If someone becomes a lawyer, a doctor, or a teacher, he necessarily determines the environment in which he will operate in the future. This increases his or her sensitivity to certain conditions of his or her

\footnotetext{
Cf. ibid., pp. 25-26.

Cf. ibid., p. 26.

Cf. ibid., pp. 27-28.

Cf. ibid., p. 35.

Cf. ibid., p. 36.

Cf. ibid., pp. 34-35.
} 
field and becomes relatively immune to things that would stimulate him if he had decided to choose another profession. ${ }^{38}$ However, if some experiences awaken curiosity, they strengthen the initiative and set the interests and needs that are intense enough to transfer the person through the 'dead spots', that is, the places where the individual is stuck in his or her development. Every piece of experience is a momentum of a certain value. According to Dewey, its value is judged, for example, by whether it is capable of transferring individuals through 'dead spots' and enabling them to further develop themselves. ${ }^{39}$ What one has learned as knowledge and ability in one situation can be used as a tool for understanding and addressing the following situations more effectively. In order for a person to become a 'whole' personality, it is essential to make his or her successive pieces of experience mutually integrated and to make them fit into the overall experience structure. Otherwise, the individual would have socialisation problems in the society where he lives, or even some personality disorders. ${ }^{40}$

\section{Conclusion}

When answering the partial research question as to how Dewey's publications developed the notion of 'experience' in the context of the theory of experiential learning, it should be noted that Dewey did not systematically work chronologically on his theory. Each part of his work brought to his theory new elements with a different focus. In the Czech environment, we understand the notion of 'experience' most often as a feeling, an experience, or experience itself. A feeling is a concrete action perceived by a person at a particular time and place, and then transformed into a form of an experience. An experience is a feeling-based memory track. It occurs more or less automatically, and its strength and depth depend on the strength and depth of previous feeling which in turn derives from the practical significance of the experienced reality, the interests, needs, and gained experience of the participant. What has greater practical value for a particular person naturally generates more powerful feelings and experiences. ${ }^{41}$ Experience is a perpetual form of a particular experienced event, of which the results are applicable in other situations as well. ${ }^{42}$

However, in John Dewey's publications I did not meet such distinctions. Exceptionally, Dewey used the terms 'inchoate experience' and 'actual experience.' The first term is the beginning and undeveloped experience, that is, Dewey's characteristic corresponds most to the abovementioned concept of feeling. The second term 'actual experience' is, according to Dewey, the change of which the target value is the transformation to the fulfilment of experience. The results of these phenomena in synergy with natural conditions can be seen as the means, techniques, and mechanisms (that is, experience) that people need for their lives. The characteristic therefore corresponds the most to the abovementioned concept of an experience.

Dewey's Theory of Experiential Learning follows the basic principle of continuity of experience. This means that each piece of experience builds on the previous one, and the subsequent piece of experience modifies previous experience and modifies or reconstructs the current experience structure of an individual. The experience contained in an individual's experience structure then influences the choice of an individual's feelings and the environment in which a particular feeling

38 Cf. DEWEY, Experience and Education..., p. 37.

39 Cf. ibid., p. 38.

40 Cf. ibid., pp. 44-45.

41 Cf. Richard MACKÜ, Metody a principy výchovy zážitkem, in: Volný čas a jeho význam ve výchově, ed. Michal KAPLÁNEK, Prague: Portál, 2017, p. 182.

42 Cf. Ivo JIRÁSEK, Teoretník, Gymnasion 1/2004, p. 14. 
will take place. Dewey uses a career choice situation as an example. If someone decides to be a doctor, he will definitely determine the range of his or her future feelings, experiences and gained experience. If he became a teacher, those would be quite different. But before he decided to be a doctor, his or her decision had been preceded by his or her experience with the field. For example, as a small child, he had been curious about the tools that doctors used to work, had been interested in the functioning of the human body, or had wanted to experience the social prestige that physicians undoubtedly have. This experience, in conjunction with other factors, especially the environment in which one lives, then led to the fact that one chooses to be a doctor. Each person gains individual experience through interaction with his or her surroundings. If it has a meaning and value for him, it is classified according to the principle of the experience continuum and inserted into the experience structure. The quality of the gained experience is directly influenced by the quality of experiences and feelings. The more intense the emotion felt by an individual during the activity, the stronger the memory of this experience will be and the more permanent the final experience will be. It will also be more difficult to 'rebuild' this experience with the following experience. Dewey understands experience as a matter with the attributes of integrity, self-identity, and individuality.

Dewey sees experience from a variety of perspectives. The first is experience as a means to a better understanding of natural cycles. According to Dewey, nature also has its own experience because natural processes and changes work similarly to the principle of the experience continuum, that is, natural processes modify each other and are linked and have their causes and consequences. Dewey therefore wants to divide experience into absolute experience which contains the sum of experience of all living beings in this world, and human experience. But only absolute experience can be the only one ever perfect, unlike human experience which is temporary, full of mistakes, conflicts, and contradictions. According to Dewey, however, man is constantly evolving primarily in the development of speech and through the processing of natural materials which are key to the cultivation of one's environment. Dewey, though, considers the natural environment (not the artificial one) to be the basic and natural one for man. Man is trying to achieve better experience and is constantly evolving and improving by nature. In this case, Dewey is influenced by Darwin's evolutionism. In addition to this, Dewey adds the claim that man has evolved from animals and hence he inherited some of the basic needs and means to satisfy those needs from animals. With these theses, for example, Emil Višňovský agrees in the book Štúdie o pragmatizme \& neopragmatizme. ${ }^{43}$

In addition, Dewey looks at the experience in connection with art and culture. Culture is a product that is not the result of the efforts of people who are left in emptiness, left to themselves, but it is the result of the long-term cumulative interaction of people with their environment. In connection with art, Dewey introduces the concept of aesthetic experience that arises from new ideas, thoughts, and solutions to new problems. Most often, the aesthetic experience manifests itself in art. According to Dewey, art and works of art represent the unification and clarification of previous experience. The work of art can be understood both as a product and as the content of experience. Dewey points to the relationship between experience, art, and nature. This is justified by the processing of natural materials and their use and display in art. People constantly produce and share objects and art because they are socially useful, significant, or precious. During production, the artists present their experience in their works of art. Dewey adds that if one adapts to his or her environment, the fulfilment culminates in a desirable sense of happiness and usefulness. Here we can trace Dewey's hints of utilitarianism. According to Dewey, one has a natural

43 Cf. Emil VIŠŇOVSKÝ, Štúdie o pragmatizme \& neopragmatizme, Bratislava: Slovenská akademie věd, 2009, pp. 116-117. 
tendency to find and repeat pleasant feelings. Above all, he has in mind the feelings connected to dance, songs, and feasts. Man has a natural tendency for seeking happiness and he desires to do good and useful things for himself and others.

Finally, Dewey looks at educational experience. Dewey generally views the theory of experiential learning as a selection of choices and the organisation of appropriate educational methods and materials needed for a new way of schooling. According to Dewey, it is necessary (in each individual's effort to achieve a certain goal) to distinguish which pieces of experience are valuable for education and which are not. For Dewey, this is a basic criterion of experience. Experience positively or negatively affects the attitudes of a person in order to help him assess the quality of other experiences (by raising certain preferences and aversions), and thus facilitates or complicates his or her behaviour. Dewey talks about experience in connection with students and the content of education. The child puts new experience in a unified experience structure in which he has stored all his or her current information about the world. This experience structure has the character of personal and social interests that life brings. Dewey, however, criticises the fact that, at school, children are given the new knowledge separately, in fragments, and often in abstract terms or contexts. The curriculum must be in line with the interests of the child according to his or her conditions. It should give the child the opportunity to explore, feel, and evaluate the work done. That way, a link is created between the important information leading to the adoption of abstract principles. Dewey notes that it is necessary to extend the child's experience. The child's experience is not final but is transient and shapeable. Dewey's Theory of Experiential Learning is also focused on educating students in order to give them the idea of an ideal democratic society. Society is constantly evolving and there is a need to respond to these changes. By learning from experience, pupils modify their actions on the basis of previous experience and better develop dispositions that will help them to resolve a similar problem in the future. The following experience complements the experience already gained and clarifies the relationships in it. Later activity thus consolidates and complements the meaning of earlier activities.

Dewey highlights the claim that the reconstruction of experience can be both social and individual. In traditional and static societies, upbringing is a process in which the child accepts the attitudes and cultural abilities of adults, primarily in order to preserve established habits and values. But in progressive society it is different. Here, through formation, society seeks to shape the experience of youth so that, instead of a mere reproduction of common customs, better relations are formed in order to have a better future society in comparison with the current one. Dewey criticises any educational concept that is based solely on preparing for a future profession and does not take into account the current student interests. Dewey again faces the integration and socialisation function of the school. The school emphasises the child's adaptation to the wider social environment and his or her independence from parents and siblings, which Dewey understands as the primary social group, the social group into which the child was born. Today we can observe the application of the principles of Dewey's theory of experiential learning, for example, in experiential pedagogy. Experiential pedagogy (also experiential education or learning by experiences) is an approach to education based on the ability of human memory to absorb pieces of information of which perception is accompanied by intense emotions. It is learning from the consequences of one's own actions, the finding of non-traditional solutions, and the overcoming of tasks and challenges together. The advantage of experiential learning is the development of creative practices, active acting, better informal relationships among individuals, and, above all, intense learning from experiences instead of the mere gathering of information. Experiential 
pedagogy works with an experience as a means of influencing the client. The direction of this influence is determined by the pedagogical goal. The work of the educator using the experiential pedagogy is based on the intentional creation of situations in which he expects intense feeling and on subsequent pedagogical work with the experience. ${ }^{44}$

\section{Contact}

\section{MA. Pavel Votava}

University of South Bohemia in České Budějovice

Faculty of Theology, Department of Pedagogy

Kněžská 8, 37001 České Budějovice

Pafka.Votava@seznam.cz 